\title{
Phylogenicity and Virulence Profiles of Clinical Escherichia coli Isolates in the Ho Teaching Hospital of Ghana
}

\author{
John Gameli Deku $\mathbb{D}^{1},{ }^{1}$ Kwabena Obeng Duedu $\mathbb{D}^{2},{ }^{2}$ Silas Kinanyok, \\ Godsway Edem Kpene $\mathbb{1}^{1},{ }^{1}$ and Patrick Kwame Feglo $\mathbb{1}^{3}$ \\ ${ }^{1}$ Department of Medical Laboratory Sciences, School of Allied Health Sciences, University of Health and Allied Sciences, Ho, Ghana \\ ${ }^{2}$ Department of Biomedical Science, School of Basic and Biomedical Sciences, University of Health and Allied Sciences, Ho, Ghana \\ ${ }^{3}$ Department of Clinical Microbiology, School of Medicine and Dentistry, KNUST, Kumasi, Ghana
}

Correspondence should be addressed to John Gameli Deku; sssdeku@gmail.com

Received 11 November 2021; Revised 5 February 2022; Accepted 14 February 2022; Published 2 March 2022

Academic Editor: Mohamed Salah Abbassi

Copyright (c) 2022 John Gameli Deku et al. This is an open access article distributed under the Creative Commons Attribution License, which permits unrestricted use, distribution, and reproduction in any medium, provided the original work is properly cited.

\begin{abstract}
Background. Escherichia coli bacteria are Gram-negative, non-spore-forming aerobes or facultative anaerobic rods. Some strains are pathogenic in men while others are commensals in the gut. The pathogenic strains cause a wide array of diseases by virtue of virulence factors. The commensal strains are generally categorized into phylogenetic groups A and B1. The aim of this study was to determine the association between phylogeny of $E$. coli isolates and virulence and sociodemographic characteristics of the study subjects. Method. This study was a cross-sectional study carried out from July 2018 to June 2019. E. coli isolates obtained from different clinical specimens were subjected to polymerase chain reaction to determine their phylogenetic groupings and virulence. Results. The majority of the isolates belonged to phylogroup A 101 (74.8\%), and the predominant virulent gene was fimA (88.9\%). There was no significant correlation between phylogenicity and virulence, except for chuA which was found in all isolates that belonged to phylogroups clade I and D. None of the 101 isolates that belonged to group A had the chuA virulence gene. There was a significant association between patient age category and phylogenetic groups B1 and D. Conclusions. This study assessed the relationship between the phylogenetic distribution and the virulence profile of clinical isolates of E. coli. The virulence of isolates belonging to phylogroup A, which are generally considered as commensals, is alarming. Measures must therefore be put in place to control the spread of these virulent $E$. coli.
\end{abstract}

\section{Introduction}

Escherichia coli bacteria are Gram-negative facultative anaerobic rods. They are non-spore-forming and possess peritrichous flagella for motility. These bacteria are potential aetiologic agents of various disease states such as cholecystitis, pneumonia, pyelonephritis, cystitis, urinary tract infection, newborn meningitis, septicaemia, central nervous, and respiratory infections [1]. However, it is worthy of note that many Escherichia coli strains are commensal resident in the gut. The barrier between commensalism and virulence of E. coli largely depends on a balance between the host immune status and the ability of the bacteria to elicit their virulence factors [2].
Extraintestinal pathogenic E. coli is one of the leading causes of morbidity and mortality globally [3]. The degree of pathogenicity of extraintestinal E. coli isolates depends on the presence of fimbriae adhesins (fimA, sfalfoc, and $y f c V$ ) which are virulent factors responsible for adherence. Adherence is a prerequisite for initiating and colonization to specific host cells [4]. Another virulent factors are haemolysins (hylA and $h y l F$ ), which are responsible for lysing red blood cells and human renal epithelial cells. Siderophores (ferric aerobactin receptor (iutA), Yersiniabactin receptor $(f y u A))$ also function to sequester iron from the host. Another virulence factor is the cytotoxic necrotizing factor (cnfl) which is implicated in tissue damage and dysfunction of a local immune response [5]. Further, the virulence gene 
encoding vacuolating toxin (vat) is accountable for delaying neutrophil infiltration of the urinary tract in response to uropathogenic $E$. coli by cleaving surface glycoproteins from leukocytes that are involved in neutrophil attraction and migration [6]. These virulence factors contribute significantly to the pathogenicity of E. coli strains by colonizing the key anatomical sites, reducing immune response, affecting physiology, and invading host tissues [7].

Before 2013, phylogenetic analysis categorized E. coli into four phylogenetic groups: A, B1, B2, and D. This classification was based on a combination of two genes (chuA and yjaA) and anonymous DNA fragment TSPE.C2 by use of polymerase chain reaction (PCR) [8]. The commensal E. coli strains were associated with phylogenetic groups A and B1 $[9,10]$. In contrast, extraintestinal pathogenic E. coli strains that carry more virulence genes belonged to phylogenetic groups B2 and D. Extraintestinal infections are mainly due to $E$. coli strains belonging to phylogroup B2 and, to a lesser extent, group D [11]. Other techniques used to determine the phylogenetic groups are multilocus enzyme electrophoresis, ribotyping, random amplified polymorphic DNA analysis, fluorescent amplified-fragment length polymorphism analysis, analysis of variance at mononucleotide repeats in intergenic sequences, and multilocus sequence typing [12].

There has been advancement in the knowledge on the multilocus sequence and genome data resulting in a better understanding of $E$. coli phylogroup classification since 2000. That notwithstanding, the available data at the time showed that $15 \%-20 \%$ of the phylogroups were incorrectly assigned [13]. Further studies have demonstrated some other unclassified strains such as phylogroup E [14], phylogroup F [13], and Escherichia cryptic clade I [8]. This drawback in the classification of the E. coli phylogroup necessitated a revised grouping of $E$. coli isolates into eight phylogroups (A, B1, B2, C, D, E, F, and Escherichia clade I) $[8]$.

In Ghana, however, data on the virulence potentials and phylogenetic groupings of extraintestinal E. coli isolates are nonexistent. Thus, this study is aimed at detecting the virulence encoding genes of $E$. coli isolates from various clinical specimens and determining their phylogenetic groups in the Ho Teaching Hospital of Ghana.

\section{Materials and Methods}

2.1. Study Design. This was a cross-sectional study consisting of $135 \mathrm{E}$. coli organisms. The isolates were obtained from various clinical samples produced by 135 patients who visited the Ho Teaching Hospital from July 2018 to June 2019. Majority, 98 (72.6\%), of these samples were urine from patients with urinary tract infection. The rest were wound swabs, 14 (10.4\%); high vaginal swabs (HVS), 10 (7.4\%); blood, 5 (3.7\%); ear swabs, 5 (3.7\%); sputum, 2 (1.5\%), and pleural aspirate, $1(0.7 \%)$.

2.2. The Bacterial Isolates. E. coli isolates were cultured from various clinical specimens, including urine, high vaginal swabs, blood on blood agar, and MacConkey agar (Oxoid, UK). Growths suspected to be E. coli were confirmed using the Gram stain reaction, triple sugar fermentation test, citrate test, urease test, indole test, Voges Proskauer, and methyl red test. The identified organisms were inoculated into $80 \%$ glycerol-Mueller Hinton broth and stored in a $-80^{\circ} \mathrm{C}$ freezer and later used for other tests. Escherichia coli ATCC 25922 and Klebsiella pneumoniae NCTC 13442 were used as control organisms.

\subsection{Molecular Detection of Virulence Factors and Phylogenetic Groups}

2.3.1. Revival of Isolates and DNA Extraction. The isolates were retrieved from the freezer, and the surface was aseptically scraped and emulsified in $30 \mathrm{ml}$ Luria Bertani broth (Oxoid, UK) and incubated overnight in a shaking incubator. Genomic deoxyribonucleic acid (DNA) was extracted from the overnight culture using a high-molecular weight phenol-chloroform extraction method [15], except that Tris-EDTA (TE) was used as the elution buffer. The extracted DNA was incubated at $4^{\circ} \mathrm{C}$ for two days to resuspend the pellet into a translucent viscous gel. The concentration of the extracted DNA was measured using a NanoDrop spectrophotometer (Thermo Scientific), and the viscous DNA was stored under $-80^{\circ} \mathrm{C}$.

\subsubsection{Detection of Virulence Genes and Phylogenetic Groups} by Polymerase Chain Reaction (PCR). Escherichia coli isolates were characterized using primer sequence from previous studies to determine the phylogenetic characteristics (Table 1) and virulence factors (Table 2). The primers were purchased from Integrated DNA Technologies, UK. OneTaq Quick-Load 2x Master Mix with standard buffer purchased from New England Biolabs ${ }^{\circledR}$ was used for the PCR. Lyophilized forward and reverse primers were reconstituted by adding a calculated amount of molecular-grade water using the nmol of the primers to give a concentration of $100 \mu \mathrm{M}$. A 1 in 10 working solution was prepared by taking $10 \mu \mathrm{l}$ of the stock and $90 \mu \mathrm{l}$ of the molecular-grade water to give $10 \mu \mathrm{M}$. A total of $12.5 \mu \mathrm{l}$ reaction volume was used, comprising 6.25 $\mu \mathrm{l}$ of OneTaq Quick-Load 2x Master Mix with standard buffer, $0.25 \mu \mathrm{l}$ each of $10 \mu \mathrm{M}$ forward and reverse primers, $1 \mu \mathrm{l}$ of template DNA, and $4.75 \mu \mathrm{l}$ of nuclease-free water.

The initial denaturation and the final elongation for both phylogenetic groups and virulence factors were carried out at $94^{\circ} \mathrm{C}$ for 30 seconds and $68^{\circ} \mathrm{C}$ for 5 minutes, respectively. For phylogenetic groups, the PCR conditions were denaturation for 30 seconds at $94^{\circ} \mathrm{C}$ and annealing for 45 seconds at $55^{\circ} \mathrm{C}$ (for chuA and $\operatorname{arp} A$ ), $51^{\circ} \mathrm{C}$ (for $y j a A$ ), $47^{\circ} \mathrm{C}$ (for TspE4.C2 and ArpAgpE), and $53^{\circ} \mathrm{C}$ (for TrpAgpC).

$\mathrm{PCR}$ conditions for the determination of virulence genes were denaturation for 30 seconds at $94^{\circ} \mathrm{C}$ and annealing for 45 seconds at $49^{\circ} \mathrm{C}$ (for ibeA), $50^{\circ} \mathrm{C}$ (for iut $A$ and $y f \mathrm{cV}$ ), $52^{\circ} \mathrm{C}$ (for fimA), $54^{\circ} \mathrm{C}$ (for $h y l F$ and $c n f 1$ ), $55^{\circ} \mathrm{C}$ (for hlyA, neuC, and $c h u A$ ), $57^{\circ} \mathrm{C}$ (for $s f a / f o c$ ), and $58^{\circ} \mathrm{C}$ (for vat and $f y u A$ ). The initial elongation was done at $68^{\circ} \mathrm{C}$ for 1 minute/kb.

The annealing temperatures for the various set of primers were calculated using the NEB Tm calculator [19]. In-house DNA (stored positive DNA from previous 
TABle 1: Primers used in the determination of phylogenetic grouping of E. coli isolates.

\begin{tabular}{|c|c|c|c|c|}
\hline Target gene & Primer ID & Primer sequences $\left(5^{\prime}-3^{\prime}\right)$ & Amplicon size (bp) & Reference \\
\hline \multirow{2}{*}{ chuA } & chuA_F & ATGGTACCGGACGAACCAAC & \multirow{2}{*}{288} & \multirow{2}{*}[8]{} \\
\hline & chuA_R & TGCCGCCAGTACCAAAGACA & & \\
\hline \multirow{2}{*}{ yjaA } & yjaA_F & CAAACGTGAAGTGTCAGGAG & \multirow{2}{*}{211} & \multirow{2}{*}[8]{} \\
\hline & yjaA_R & AATGCGTTCCTCAACCTGTG & & \\
\hline \multirow{2}{*}{ TspE4.C2 } & TsepC4.C2_F & CACTATTCGTAAGGTCATCC & \multirow{2}{*}{152} & \multirow{2}{*}[8]{} \\
\hline & TsepC4.C2_R & AGTTTATCGCTGCGGGTCGC & & \\
\hline \multirow{2}{*}{$\operatorname{arp} A$} & arpA_F & AACGCTATTCGCCAGCTTGC & \multirow{2}{*}{400} & \multirow{2}{*}{ [8] } \\
\hline & arpA_R & TCTCCCCATACCGTACGCTA & & \\
\hline \multirow{2}{*}{$\operatorname{ArpAgpE}$} & ArpAgpE_F & GATTCCATCTTGTCAAAATATGCC & \multirow{2}{*}{301} & \multirow{2}{*}[16]{} \\
\hline & ArpAgpE_R & GAAAAGAAAAAGAATTCCCAAGAG & & \\
\hline \multirow{2}{*}{$\operatorname{TrpAgpC}$} & trpAgpC_F & AGTTTTATGCCCAGTGCGAG & \multirow{2}{*}{219} & \multirow{2}{*}[16]{} \\
\hline & $\operatorname{trp} A g p C \_R$ & TCTGCGCCGGTCACGCCC & & \\
\hline
\end{tabular}

TABLE 2: Oligonucleotide primers used to detect virulence genes.

\begin{tabular}{|c|c|c|c|c|}
\hline Target gene & Primer ID & Primer sequence $\left(5^{\prime}-3^{\prime}\right)$ & Amplicon size (bp) & Reference \\
\hline \multirow{2}{*}{$i b e A$} & ibeA_F & TGAACGTTTCGGTTGTTTTG & \multirow{2}{*}{814} & \multirow{2}{*}[17]{} \\
\hline & ibeA_R & TGTTCAAATCCTGGCTGGAA & & \\
\hline \multirow{2}{*}{ hlyA } & hylA_F & AACAAGGATAAGCACTGTTCTGGC & \multirow{2}{*}{1177} & \multirow{2}{*}[17]{} \\
\hline & hylA_R & ACCATATAAGCGGTCATTCCCGTCA & & \\
\hline \multirow{2}{*}{$h l y F$} & hylF_F & TCGTTTAGGGTGCTTACCTTCAAC & \multirow{2}{*}{444} & \multirow{2}{*}[17]{} \\
\hline & hylF_R & TTTGGCGGTTTAGGCATTCC & & \\
\hline \multirow{2}{*}{ neuC } & neuC_F & AGGTGAAAAGCCTGGTAGTGTG & \multirow{2}{*}{676} & \multirow{2}{*}[17]{} \\
\hline & neuC_R & GGTGGTACATCCCGGGATGTC & & \\
\hline \multirow{2}{*}{ iutA } & iutA_F & ATGAGCATATCTCCGGACG & \multirow{2}{*}{587} & \multirow{2}{*}[17]{} \\
\hline & iutA_R & CAGGTCGAAGAACATCTGG & & \\
\hline \multirow{2}{*}{$s f a / f o c$} & sfa/foc_F & CTCCGGAGAACTGGGTGCATCTTAC & \multirow{2}{*}{410} & \multirow{2}{*}[17]{} \\
\hline & sfa/foc_R & CGGAGGAGTAATTACAAACCTGGCA & & \\
\hline \multirow{2}{*}{ fimA } & fimA_F & CGGCTCTGTCCCTSAGT & \multirow{2}{*}{500} & \multirow{2}{*}{ [17] } \\
\hline & fimA_R & GTCGCATCCGCATTAGC & & \\
\hline \multirow{2}{*}{$y f c V$} & yfcV_F & ACATGGAGACCACGTTCACC & \multirow{2}{*}{292} & \multirow{2}{*}[18]{} \\
\hline & yfcV_R & GTAATCTGGAATGTGGTCAGG & & \\
\hline \multirow{2}{*}{$\operatorname{cnf} 1$} & cnf 1_F & AAGATGGAGTTTCCTATGCAGGAG & \multirow{2}{*}{498} & \multirow{2}{*}[17]{} \\
\hline & cnf 1_R & CATTCAGAGTCCTGCCCTCATTATT & & \\
\hline \multirow{2}{*}{ vat } & vat_F & TCAGGACACGTTCAGGCATTCAGT & \multirow{2}{*}{1100} & \multirow{2}{*}[18]{} \\
\hline & Vat_R & GGCCAGAACATTTGCTCCCTTGTT & & \\
\hline \multirow{2}{*}{ fyuA } & fyuA_F & F_GTAAACAATCTTCCCGCTCGGCAT & \multirow{2}{*}{850} & \multirow{2}{*}{ [18] } \\
\hline & fyuA_R & R_TGACGATTAACGAACCGGAAGGGA & & \\
\hline
\end{tabular}

experiments) in the laboratory were used as positive controls whereas the Ambion ${ }^{\circledR}$ Nuclease-free Water (Life Technologies, USA) was used as negative control. Thermocycling was done for 30 cycles.

2.3.3. Loading of Amplicons. Using a micropipette, the resulting PCR products were loaded into agarose wells. The first and second lanes were loaded with $6 \mu \mathrm{l}$ of the either $50 \mathrm{bp}, 100 \mathrm{bp}$, or $1 \mathrm{~kb}$ DNA ladder and $10 \mu \mathrm{l}$ of in-housegenerated positive DNA samples. The last lane was loaded with sterile nuclease-free water which served as a negative control test. The remaining lanes were loaded with samples under investigation.

2.4. Statistical Analysis. All analyses were conducted using the SPSS version 25 software and GraphPad Prism 6. Variables were expressed as percentages (\%), and the chisquare test was performed to assess the relationships between variables. Variables such as the virulence genes and phylogenetic groups of the E. coli strains and 
sociodemographic and socioeconomic characteristics of patients were considered for the chi-square analysis. $P$ values $<0.05$ were considered statistically significant.

2.5. Ethical Considerations. Ethical clearance for the study was granted by the Joint Committee on Human Research, Publication and Ethics (CHRPE), School of Medical Sciences and Dentistry, and Komfo Anokye Teaching Hospital, with the protocol number CHRPE/AP/204/18.

\section{Results}

A total of 135 clinical isolates of E. coli were recovered from the various clinical specimens of patients who visited the Ho Teaching Hospital for medical care. Only $1(0.7 \%)$ isolate was recovered from the pleural aspirate whereas multiple isolates $98(72.6 \%)$ were recovered from the urine samples of patients with urinary tract infections. The proportion of isolates from the other samples was $14(10.4 \%)$ from wound swabs, 10 (7.4\%) from HVS, 5 (3.7\%) each from blood and ear swabs, and $2(1.5 \%)$ from sputum. The relationship between sociodemographic and patients' characteristics and the phylogeny of E. coli isolates is presented in Table 3. The majority of the isolates (82.2\%) came from women, and by the type of patients, the majority was from outpatients $(72.6 \%)$. There was no significant difference between the proportion of isolates in each phylogroup when compared by gender. Similarly, there was no significant difference between the proportion of phylogroups when compared by the other demographic characteristics (religion, marital status, and occupation), sample type (urine or non-urine), and patient type (out- or in-patient). Age wise, there was no statistically significant difference between the proportion of isolates by phylogroups except for isolates that belonged to phylogroup B1 $(P=0.017)$ and $\mathrm{D}(P=0.007)$.

Phylogenetic analysis segregated the $135 \mathrm{E}$. coli isolates into phylogenetic groups A 101 (74.8\%), B1 3(2.2\%), B2 20 (14.8\%), C 4(3.0\%), clade I 2(1.5\%), and D 5(3.7\%).

A total of 12 different virulence genes were identified with the clinical isolates. The virulent gene fimA 120 (88.9\%) was the most prevalent, while three (3) of the remaining were prevalent in more than $50 \%$ of the isolates (fyuA 106 (78.5\%), yfcV 104 (77.0\%), and iutA 88 (65.2\%)). On the other hand, three of the virulence genes under investigation were identified in less than $15 \%$ of the total isolates (chuA 18 (13.3\%), ibeA 16 (11.9\%), and $h l y F 7(5.2 \%)$ ). Other virulence genes identified were vat 56 (41.5\%), hylA 41 (30.4\%), neuC 40 (29.6\%), cnf 139 (28.9\%), and sfalfoc 37 (27.4\%).

Table 3 presents the relationship between sociodemographic and patients' characteristics and the phylogeny of $E$. coli isolates. There is a significant association between patient's age category and phylogenetic groups B1 and D.

Chi-square analysis for the correlation between virulence genes and the phylogenetic groups of isolates showed no correlation between the two except for the virulence gene ChuA $(P<0.0001)$ where the proportions of clade 1 and $\mathrm{D}$ were higher than those of the others. The distribution also presented that none of the 101 isolates belonging to group
A had the chuA virulence gene. Similarly, none of the B1 and $\mathrm{C}$ phylogroups possessed the $C h u A$ virulence gene. Details of these results can be found in Table 4 .

\section{Discussion}

This study investigated the virulence profile and phylogenetic characteristics of extraintestinal pathogenic E. coli. Majority of the organisms were recovered from urine samples received from patients with urinary tract infections. Our finding is consistent with a study by Lara et al. [20] who reported that urinary tract infections are the most common extraintestinal infection caused by E. coli. Our study reported that most of the uropathogenic E. coli belongs to phylogenetic group A. The preponderance of phylogenetic group A in uropathogenic E. coli isolates which is usually associated with commensal strains suggests that the gastrointestinal tract is the main source of strains that colonize the urinary tract [21].

Due to the pathogenicity of $E$. coli, it is an important cause of extraintestinal infections in health facilities around the globe. The E. coli organism must first adhere to the host cell to establish infection, and this is achieved by its surface adhesins [22]. The current study investigated the presence of $f i m A, y f c v$, and $s f a / f o c$ virulence genes responsible for adhesions. These genes were detected in $88.9 \%, 77.0 \%$, and $27.4 \%$ of the E. coli isolates, respectively. Similar results were reported in other parts of the world for $s f a / f o c$ genes $[3,23]$ and fimA genes $[24,25]$. These plasmid-encoded fimA genes were commonly found in isolates from infection at the lower urinary tract, where they adhere to the urethral mucosa epithelial cells [24].

In the present study, haemolysin-encoding genes, $h l y A$ and $h l y F$, were present in $30.4 \%$ and $5.2 \%$ of the isolates respectively. A higher percentage of $h l y$-encoding genes (41.2\%) among the E. coli isolates was observed in Japan [26]. Contrary to our finding, Agarwal et al. [27] in India reported a lower prevalence of $4.7 \%$ of $E$. coli isolates carrying haemolysin genes in women suffering from acute cystitis. HlyA is a pore-forming exotoxin secreted to lyse red blood cells and human renal epithelial cells by creating pores in them. The E. coli organisms utilize the iron released from the lysed erythrocytes through the siderophore system. Its production and expression are controlled by the availability of iron [28]. A high proportion of $h l y A$ recorded in this study belonged to phylogroup $\mathrm{D}$, which corroborates the finding of Zhang et al. [29]. That study reported that highly haemolytic isolates belonged to phylogroup D.

Most of the E. coli isolates in this study belonged to phylogenetic group A (74.8\%). Our finding contradicted the study by Iranpour et al. [16], who reported phylogenetic group A minority (0.7\%). A plausible reason for this observation could be the difference in sample characteristics; while in their study, they used E. coli isolates from patients with urinary tract infections, our study involved not only urine samples. Although isolates belonging to this phylogenetic group were generally regarded as commensals in the gastrointestinal tract, they transcended the gut and had access to the urinary tract and caused infections. This could 
TABLE 3: Relationship between sociodemographic characteristics of study participants and the phylogenetic groups of E. coli.

\begin{tabular}{|c|c|c|c|c|c|c|c|c|c|c|c|c|c|}
\hline Phylogroups & Total & $\begin{array}{c}\mathrm{A} \\
(n=101)\end{array}$ & $\begin{array}{c}\mathrm{P} \\
\text { value }\end{array}$ & $\begin{array}{c}\text { B1 } \\
(n=3)\end{array}$ & $\begin{array}{c}P \\
\text { value }\end{array}$ & $\begin{array}{c}\text { B2 } \\
(n=20)\end{array}$ & $\begin{array}{c}P \\
\text { value }\end{array}$ & $\begin{array}{c}\mathrm{C} \\
(n=4)\end{array}$ & $\begin{array}{c}P \\
\text { value }\end{array}$ & $\begin{array}{c}\text { Clade } 1 \\
(n=2)\end{array}$ & $\begin{array}{c}P \\
\text { value }\end{array}$ & $\begin{array}{c}\mathrm{D} \\
(n=5)\end{array}$ & $\begin{array}{c}P \\
\text { value }\end{array}$ \\
\hline \multicolumn{14}{|l|}{ Sex } \\
\hline Male & 24 & $16(66.7)$ & 0.311 & $0(0.0)$ & 1.000 & $5(20.8)$ & 0.353 & $1(4.2)$ & 0.547 & $1(4.2)$ & 0.325 & $1(4.2)$ & 1.000 \\
\hline Female & 111 & $85(76.6)$ & & $3(0.3)$ & & $15(13.5)$ & & $3(2.7)$ & & $1(0.9)$ & & $4(3.6)$ & \\
\hline \multicolumn{14}{|l|}{ Age } \\
\hline$<10$ & 11 & $7(63.3)$ & 0.058 & $2(18.2)$ & 0.017 & $1(9.1)$ & 0.064 & $0(0.0)$ & 0.154 & $1(9.1)$ & 0.386 & $0(0.0)$ & 0.007 \\
\hline $10-19$ & 2 & $0(0.0)$ & & $0(0.0)$ & & $1(50)$ & & $0(0.0)$ & & $0(0.0)$ & & $1(50)$ & \\
\hline $20-29$ & 26 & $17(65.4)$ & & $1(3.9)$ & & $7(26.9)$ & & $0(0.0)$ & & $0(0.0)$ & & $1(3.9)$ & \\
\hline $30-39$ & 32 & $29(90.6)$ & & $0(0.0)$ & & $2(6.25)$ & & $0(0.0)$ & & $1(3.1)$ & & $0(0.0)$ & \\
\hline $40-49$ & 19 & $14(73.7)$ & & $0(0.0)$ & & $5(26.3)$ & & $0(0.0)$ & & $0(0.0)$ & & $0(0.0)$ & \\
\hline $50-59$ & 16 & $12(75.0)$ & & $0(0.0)$ & & $0(0.0)$ & & $2(12.5)$ & & $0(0.0)$ & & $2(12.5)$ & \\
\hline$\geq 60$ & 29 & $22(75.9)$ & & $0(0.0)$ & & $4(14.0)$ & & $2(7.0)$ & & $0(0.0)$ & & $1(3.5)$ & \\
\hline \multicolumn{14}{|l|}{ Religion } \\
\hline Christian & 128 & $95(74.2)$ & 0.307 & $3(2.3)$ & 0.920 & $19(14.8)$ & 0.243 & $4(3.1)$ & 0.893 & $2(1.6)$ & 0.946 & $5(3.9)$ & 0.868 \\
\hline Islam & 2 & $1(50.0)$ & & $0(0.0)$ & & $1(50.0)$ & & $0(0.0)$ & & $0(0.0)$ & & $0(0.0)$ & \\
\hline None & 5 & $5(100.0)$ & & $0(0.0)$ & & $0(0.0)$ & & $0(0.0)$ & & $0(0.0)$ & & $0(0.0)$ & \\
\hline \multicolumn{14}{|l|}{ Marital status } \\
\hline Single & 46 & $29(63.0)$ & 0.104 & $2(4.4)$ & 0.687 & $8(17.4)$ & 0.770 & $3(6.5)$ & 0.377 & $1(2.2)$ & 0.965 & $3(6.5)$ & 0.653 \\
\hline Married & 84 & $67(79.8)$ & & $1(1.2)$ & & $12(14.3)$ & & $1(1.2)$ & & $1(1.2)$ & & $2(2.4)$ & \\
\hline Cohabiting & 3 & $3(100.0)$ & & $0(0.0)$ & & $0(0.0)$ & & $0(0.0)$ & & $0(0.0)$ & & $0(0.0)$ & \\
\hline Widowed & 2 & $2(100.0)$ & & $0(0.0)$ & & $0(0.0)$ & & $0(0.0)$ & & $0(0.0)$ & & $0(0.0)$ & \\
\hline \multicolumn{14}{|l|}{ Occupation } \\
\hline Unemployed & 53 & $39(73.6)$ & 0.773 & $3(5.7)$ & 0.093 & $6(11.3)$ & 0.251 & $3(5.7)$ & 0.285 & $1(1.9)$ & 0.945 & $1(1.9)$ & 0.096 \\
\hline Formal & 34 & $27(79.4)$ & & $0(0.0)$ & & $8(23.5)$ & & $0(0.0)$ & & $1(2.9)$ & & $0(0.0)$ & \\
\hline Informal & 48 & $35(72.9)$ & & $0(0.0)$ & & $6(1.3)$ & & $1(2.1)$ & & $1(2.1)$ & & $4(4.3)$ & \\
\hline \multicolumn{14}{|l|}{ Specimen } \\
\hline Nonurine & 37 & $25(67.6)$ & 0.269 & $1(2.7)$ & 1.000 & $8(21.6)$ & 0.183 & $1(2.7)$ & 1.000 & $1(2.7)$ & 0.475 & $0(0.0)$ & 0.322 \\
\hline Urine & 98 & $76(77.6)$ & & $2(2.0)$ & & $12(12.5)$ & & $3(3.1)$ & & $1(1.0)$ & & $5(5.1)$ & \\
\hline \multicolumn{14}{|l|}{ Patient status } \\
\hline Outpatient & 98 & $74(75.5)$ & 0.825 & $3(3.1)$ & 0.561 & $16(16.3)$ & 0.589 & $1(1.0)$ & 0.068 & $2(2.0)$ & 1.000 & $2(2.0)$ & 0.126 \\
\hline Inpatient & 37 & $27(73.0)$ & & $0(0.0)$ & & $4(14.2)$ & & $3(8.1)$ & & $0(0.0)$ & & $3(8.1)$ & \\
\hline
\end{tabular}

be due to the availability of functional genes that directly contribute to pathogenesis or the presence of certain putative factors enabling successful colonization of the host that enhances fitness and adaptation of the bacteria to their surroundings [16] According to Ochman et al. [30], commensal E. coli can acquire chromosomal or extrachromosomal virulence operons and become pathogenic.

In furtherance to that, commensal strains may become virulent by a genomic deletion that enhances pathogenicity and random functional point mutations adaptive for pathogenic environments [31]. However, it is unclear whether $E$. coli isolates should be defined as commensals or pathogens based wholly on the source of the specimen and/or phylogenetic group they belong to since phylogroups A and B1 can cause extraintestinal infections in immunocompromised hosts at a point in time [32]. The pathogenicity of E. coli isolates belonging to phylogenetic group $\mathrm{A}$ is at variance with other studies that categorized pathogenic E. coli isolates into phylogenetic groups B2 and D $[33,34]$. Our finding is comparable to other studies in other parts of the globe that reported phylogroup A majority $[35,36]$. The prevalence of B1 and B2 phylogroups found in the current study are lower than those reported in Abidjan [37]. The three predominant phylogroups, A, B2, and D, reported in our study agree with those stated by Derakhshandeh et al. [38] but at variance with those described by Iranpour et al. [16]. The variations in the distribution of the phylogenetic groups reported in different studies may be due to the health status of the host, geographical and climatic conditions, dietary factors, antibiotic usage, host genetic factors, and the differences arising from different sampling methods [38].

In addition to the four main phylogroups (A, B1, B2, and D) previously reported, the new Clermont quadruplex PCR method of $E$. coli discrimination added four new phylogroups made up of $\mathrm{C}, \mathrm{E}, \mathrm{F}$, and clade I. In this current study, $4(3.0 \%)$ of the isolates belonged to phylogroup $\mathrm{C}$ 
TABLE 4: Association between phylogenetic groups and virulence genes of $E$. coli isolates from clinical specimen.

\begin{tabular}{|c|c|c|c|c|c|c|c|c|c|}
\hline \multirow{2}{*}{$\begin{array}{l}\text { V. gene } \\
\text { Phlyo-group }\end{array}$} & \multicolumn{2}{|c|}{ ChuA } & \multirow{2}{*}{$P$ value } & \multicolumn{2}{|c|}{ neuC } & \multirow{2}{*}{$P$ value } & \multicolumn{2}{|c|}{ Sfalfoc } & \multirow{2}{*}{$P$ value } \\
\hline & Present & Absent & & Present & Absent & & Present & Absent & \\
\hline $\mathrm{A}$ & $0(0.0)$ & $101(100)$ & \multirow{7}{*}{$<0.0001$} & $30(29.7)$ & $71(70.3)$ & & $28(27.7)$ & $73(72.3)$ & \multirow{7}{*}{0.642} \\
\hline B1 & $0(0.0)$ & $3(100.0)$ & & $1(33.3)$ & $2(66.7)$ & & $0(0.0)$ & $3(100.0)$ & \\
\hline B2 & $11(55.0)$ & $9(45.0)$ & & $6(30.0)$ & $14(70.0)$ & & $5(25.0)$ & $15(75.0)$ & \\
\hline $\mathrm{C}$ & $0(0.0)$ & $4(100.0)$ & & $0(0.0)$ & $4(100.0)$ & 0.246 & $2(50.0)$ & $2(50.0)$ & \\
\hline Clade I & $2(100.0)$ & $0(0.0)$ & & $2(100.0)$ & $0(0.0)$ & & $0(0.0)$ & $2(100.0)$ & \\
\hline $\mathrm{D}$ & $5(100.0)$ & $0(0.0)$ & & $1(20.0)$ & $4(80.0)$ & & $2(40.0)$ & $3(60.0)$ & \\
\hline Total & $18(13.3)$ & $117(86.7)$ & & $40(29.6)$ & $95(70.4)$ & & $37(27.4)$ & $98(72.6)$ & \\
\hline V. gene & \multicolumn{2}{|c|}{ fimA } & \multirow{2}{*}{$P$ value } & \multicolumn{2}{|c|}{ iutA } & & \multicolumn{2}{|c|}{ cnfl } & \multirow{2}{*}{$P$ value } \\
\hline Phlyo-group & Present & Absent & & Present & Absent & $P$ value & Present & Absent & \\
\hline A & $90(89.1)$ & $11(10.9)$ & \multirow{7}{*}{0.6454} & $69(68.3)$ & $32(31.7)$ & & $27(26.7)$ & $74(73.3)$ & \multirow{7}{*}{0.637} \\
\hline B1 & $3(100.0)$ & $0(0.0)$ & & $1(33.3)$ & $2(66.7)$ & & $0(0.0)$ & $3(100.0)$ & \\
\hline B2 & $16(80.0)$ & $4(20.0)$ & & $10(50.0)$ & $10(50.0)$ & & $7(35.0)$ & $13(65.0)$ & \\
\hline $\mathrm{C}$ & $4(100.0)$ & $0(0.0)$ & & $3(75.0)$ & $1(25.0)$ & 0.403 & $2(50.0)$ & $2(50.0)$ & \\
\hline Clade 1 & $2(100.0)$ & $0(0.0)$ & & $2(100.0)$ & $0(0.0)$ & & $1(50.0)$ & $1(50.0)$ & \\
\hline $\mathrm{D}$ & $5(100.0)$ & $0(0.0)$ & & $3(60.0)$ & $2(40.0)$ & & $2(40.0)$ & $3(60.0)$ & \\
\hline Total & $120(88.9)$ & $15(11.1)$ & & $88(65.2)$ & $47(34.8)$ & & $39(28.9)$ & $96(71.1)$ & \\
\hline $\mathrm{V}$. gene & \multicolumn{2}{|c|}{$h l y A$} & $P$ palu & \multicolumn{2}{|c|}{$h l y F$} & & \multicolumn{2}{|c|}{$i b e A$} & \multirow{4}{*}{$P$ value } \\
\hline Phlyo-group & Present & Absent & $P$ value & Present & Absent & & Present & Absent & \\
\hline A & $30(29.7)$ & $71(70.3)$ & & $4(4.0)$ & $97(96.0)$ & & $12(11.9)$ & $89(88.1)$ & \\
\hline B1 & $0(0.0)$ & $3(100.0)$ & & $0(0.0)$ & $3(100.0)$ & & $0(0.0)$ & $3(100.0)$ & \\
\hline B2 & $6(30.0)$ & $14(70.0)$ & \multirow{5}{*}{0.415} & $3(15.0)$ & $17(85.0)$ & & $3(15.0)$ & $17(85.0)$ & \multirow{5}{*}{0.468} \\
\hline $\mathrm{C}$ & $2(50.0)$ & $2(50.0)$ & & $0(0.0)$ & $4(100.0)$ & 0.417 & $0(0.0)$ & $4(100.0)$ & \\
\hline Clade 1 & $0(0.0)$ & $2(100.0)$ & & $0(0.0)$ & $2(100.0)$ & & $1(50.0)$ & $1(50.0)$ & \\
\hline $\mathrm{D}$ & $3(60.0)$ & $2(40.0)$ & & $0(0.0)$ & $5(100.0)$ & & $0(0.0)$ & $5(100.0)$ & \\
\hline Total & $41(30.4)$ & $94(69.6)$ & & $7(5.2)$ & $128(94.8)$ & & $16(11.9)$ & $119(88.1)$ & \\
\hline V. gene & \multicolumn{2}{|c|}{ vat } & $P$ value & \multicolumn{2}{|c|}{$y f c V$} & $P$ value & \multicolumn{2}{|c|}{ fyuA } & \multirow{5}{*}{$P$ value } \\
\hline Phlyo-group & Present & Absent & & Present & Absent & t vatue & Present & Absent & \\
\hline A & $42(41.6)$ & $59(58.4)$ & & $80(79.2)$ & $21(20.8)$ & & $79(78.2)$ & $22(21.8)$ & \\
\hline B1 & $1(33.3)$ & $2(66.7)$ & & $1(33.3)$ & $2(66.7)$ & & $2(66.7)$ & $1(33.3)$ & \\
\hline B2 & $9(45.0)$ & $11(55.0)$ & & $14(70.0)$ & $6(30.0)$ & & $16(80.0)$ & $4(20.0)$ & \\
\hline $\mathrm{C}$ & $0(0.0)$ & $4(100.0)$ & 0.322 & $3(75.0)$ & $1(25.0)$ & 0.458 & $3(75.0)$ & $1(25.0)$ & 0.973 \\
\hline Clade 1 & $2(100.0)$ & $0(0.0)$ & & $2(100.0)$ & $0(0.0)$ & & $2(100.0)$ & $0(0.0)$ & \\
\hline $\mathrm{D}$ & $2(40.0)$ & $3(60.0)$ & & $4(80.0)$ & $1(20.0)$ & & $4(80.0)$ & $1(20.0)$ & \\
\hline Total & $56(41.5)$ & $79(58.5)$ & & $104(77.0)$ & $31(23.0)$ & & $106(78.5)$ & $29(21.5)$ & \\
\hline
\end{tabular}

Data are presented as frequencies with corresponding percentages in parenthesis. Phlyo: phylogenetic; V: virulence.

and $2(1.5 \%)$ to clade I. In total, our study reported that 6 (4.4\%) of the E. coli isolates belonged to the newly described phylogroups against the $13 \%$ by Clermont et al. [8] and $25 \%$ by Iranpour et al. [16]. This difference in phylogenetic distribution could be due to socioeconomic factors of the study population, climatic conditions, hygienic status, and dietary habits of the host [39].

A significant association was observed with patients' age and phylogenic groups B1 and D in the present study. There are divergent views by various scientists on the impact of age on the phylogenetic distribution of E. coli isolates. For instance, Escobar-Páramo et al. [40], in their study, established a link between phylogenicity and patients' age. Their findings were consistent with other studies [41, 42]. On the other hand, a Chinese report did not find any significant difference in the phylogenetic group composition and the age of the patients [43]. The present study did not show any significant difference in the phylogenetic grouping and sociodemographic characteristics of study participants' gender, occupation, marital status, religion, and admission status) except for age. It supports the study by Iranpour et al. [16], who likewise reported no statistical difference in phylogenetic characteristics and patients' gender.

\section{Conclusions}

In conclusion, this study assessed the relationship between the phylogenetic distribution and the virulence profile of 
clinical isolates of E. coli. Most of the isolates studied belonged to phylogenetic group A and carried essential factors responsible for virulence and pathogenicity. The virulent genes included adhesin (fimA, $y f c v$, and sfa/foc) and haemolysin ( $h l y A$ and $h l y F)$. Patients' age was significantly observed to be associated with phylogenic groups B1 and D. However, there was no association between virulence genes and phylogenetic distribution except $c h u A$ which was found in all phylogroups $\mathrm{D}$ and clade I isolates. The virulence of isolates belonging to phylogroup A, generally considered commensals, is alarming. Therefore, measures must be put in place to control the spread of these virulent strains E. coli.

\section{Data Availability}

Data is obtainable from the corresponding author upon satisfactory request.

\section{Conflicts of Interest}

The authors declare that there is no conflict of interest.

\section{Acknowledgments}

The authors are grateful to the staff of Duedu laboratory and the Ho Teaching Hospital laboratory for their support.

\section{References}

[1] M. S. Abdul-Razzaq and L. A. Abdul-Lateef, "Molecular phylogeny of Escherichia coli isolated from clinical samples in Hilla, Iraq," African Journal of Biotechnology, vol. 10, no. 70, pp. 15783-15787, 2011.

[2] B. Picard, J. S. Garcia, S. Gouriou et al., "The link between phylogeny and virulence inEscherichia colieExtraintestinal infection," Infection and Immunity, vol. 67, no. 2, pp. 546-553, 1999.

[3] N. Adib, R. Ghanbarpour, H. Solatzadeh, and H. Alizade, "Antibiotic Resistance Profile and Virulence Genes of Uropathogenic Escherichia Coli Isolates in Relation to Phylogeny," Trop Biomed, vol. 31, no. 1, pp. 17-25, 2014.

[4] K. Melican, R. M. Sandoval, A. Kader et al., "Uropathogenic Escherichia coli $\mathrm{P}$ and Type 1 fimbriae act in synergy in a living host to facilitate renal colonization leading to nephron obstruction," PLoS Pathogens, vol. 7, no. 2, article e1001298, 2011.

[5] D. Farrell, I. Morrissey, D. De Rubeis, and M. Robbins, "A UK multicentre study of the antimicrobial susceptibility of bacterial pathogens causing urinary tract infection," Journal of Infection, vol. 46, no. 2, pp. 94-100, 2003.

[6] F. Ruiz-Perez, R. Wahid, C. S. Faherty et al., "Serine protease autotransporters from Shigella flexneri and pathogenic Escherichia coli target a broad range of leukocyte glycoproteins," Proceedings of the National Academy of Sciences, vol. 108, no. 31, pp. 12881-12886, 2011.

[7] K. S. Abdallah, Y. Cao, and D. J. Wei, "Epidemiologic investigation of extra-intestinal pathogenic E. coli (ExPEC) based on PCR phylogenetic group and fimH single nucleotide polymorphisms (SNPs) in China," International Journal of Molecular Epidemiology and Genetics, vol. 2, no. 4, pp. 339-353, 2011.
[8] O. Clermont, J. K. Christenson, E. Denamur, and D. M. Gordon, "The ClermontEscherichia coliphylo-typing method revisited: improvement of specificity and detection of new phylo-groups," Environmental Microbiology Reports, vol. 5, no. 1, pp. 58-65, 2013.

[9] F. L. Nowrouzian, A. E. Wold, and I. Adlerberth, "Escherichia coli strains belonging to phylogenetic group B2 have superior capacity to persist in the intestinal microflora of infants," The Journal of infectious diseases, vol. 191, no. 7, pp. 1078-1083, 2005.

[10] R. M. Khairy, E. S. Mohamed, H. M. Abdel Ghany, and S. S. Abdelrahim, "Phylogenic classification and virulence genes profiles of uropathogenic E. coli and diarrhegenic E. coli strains isolated from community acquired infections," PLoS One, vol. 14, no. 9, article e0222441, 2019.

[11] S. Bashir, A. Haque, Y. Sarwar, A. Ali, and M. I. Anwar, "Virulence profile of different phylogenetic groups of locally isolated community acquired uropathogenic E. coli from Faisalabad region of Pakistan," Annals of Clinical Microbiology and Antimicrobials, vol. 11, no. 1, pp. 1-6, 2012.

[12] S. D. Reid, C. J. Herbelin, A. C. Bumbaugh, R. K. Selander, and T. S. Whittam, "Parallel evolution of virulence in pathogenic Escherichia coli," Nature, vol. 406, no. 6791, pp. 64-67, 2000.

[13] O. Clermont, M. Olier, C. Hoede et al., "Animal and human pathogenic_Escherichia coli_strains share common genetic backgrounds," Infection, Genetics and Evolution, vol. 11, no. 3, pp. 654-662, 2011.

[14] O. Tenaillon, D. Skurnik, B. Picard, and E. Denamur, "The population genetics of commensal_Escherichia coli_," Nature Reviews Microbiology, vol. 8, no. 3, pp. 207-217, 2010.

[15] June 2019 https://www.protocols.io/view/ultra-long-readsequencing-protocol-for-rad004-mrxc57n.

[16] D. Iranpour, M. Hassanpour, H. Ansari, S. Tajbakhsh, G. Khamisipour, and A. Najafi, "Phylogenetic groups of Escherichia coli strains from patients with urinary tract infection in Iran based on the new Clermont phylotyping method," BioMed Research International, vol. 2015, 7 pages, 2015.

[17] M. Moulin-Schouleur, M. Répérant, S. Laurent et al., "Extraintestinal pathogenicEscherichia colistrains of avian and human origin: link between phylogenetic relationships and common virulence patterns," Journal of Clinical Microbiology, vol. 45, no. 10, pp. 3366-3376, 2007.

[18] R. R. Spurbeck, P. C. Dinh Jr., S. T. Walk et al., "Escherichia coli isolates that carryvat,fyuA,chuA, andyfcVefficiently colonize the urinary tract," Infection and Immunity, vol. 80, no. 12 , pp. $4115-4122$.

[19] September, 2019 http://www.neb.com/TmCalculator.

[20] F. Lara, D. R. Nery, P. M. de Oliveira et al., "Virulence markers and phylogenetic analysis of Escherichia coli strains with hybrid EAEC/UPEC genotypes recovered from sporadic cases of extraintestinal infections," Frontiers in Microbiology, vol. 8, p. 146, 2017.

[21] D. A. López-Banda, E. M. Carrillo-Casas, M. Leyva-Leyva et al., "Identification of virulence factors genes in Escherichia coli isolates from women with urinary tract infection in Mexico," BioMed Research International, vol. 2014, Article ID 959206, 10 pages, 2014.

[22] J. Sarowska, B. Futoma-Koloch, A. Jama-Kmiecik et al., "Virulence factors, prevalence and potential transmission of extraintestinal pathogenic Escherichia coli isolated from different sources: recent reports," Gut Pathogens, vol. 11, no. 1, pp. 116, 2019. 
[23] M. R. Tiba, T. Yano, and D. S. Leite, "Genotypic characterization of virulence factors in Escherichia coli strains from patients with cystitis," Revista do Instituto de Medicina Tropical de São Paulo, vol. 50, no. 5, pp. 255-260, 2008.

[24] E. D. Candan and N. Aksöz, "Escherichia coli: characteristics of carbapenem resistance and virulence factors," Brazilian Archives of Biology and Technology, vol. 60, 2017.

[25] A. Kaczmarek, K. Skowron, A. Budzyńska, and E. Gospodarek-Komkowska, "Virulence-associated genes and antibiotic susceptibility among vaginal and rectal Escherichia coli isolates from healthy pregnant women in Poland," Folia Microbiologica, vol. 63, no. 5, pp. 637-643, 2018.

[26] S. Yamamoto, "Molecular epidemiology of uropathogenic Escherichia coli," Journal of Infection and Chemotherapy, vol. 13, no. 2, pp. 68-73, 2007.

[27] J. Agarwal, B. Mishra, S. Srivastava, and R. Srivastava, "Genotypic characteristics and biofilm formation among Escherichia coli isolates from Indian women with acute cystitis," Transactions of The Royal Society of Tropical Medicine and Hygiene, vol. 107, no. 3, pp. 183-187, 2013.

[28] M. Katouli, "Population structure of gut Escherichia coli and its role in development of extra-intestinal infections," Iranian Journal of Microbiology, vol. 2, no. 2, pp. 59-72, 2010.

[29] W. Zhang, B. Kohler, E. Oswald et al., "Genetic diversity of intimin genes of attaching and effacingEscherichia colistrains," Journal of Clinical Microbiology, vol. 40, no. 12, pp. 4486-4492, 2002.

[30] H. Ochman, J. G. Lawrence, and E. A. Groisman, "Lateral gene transfer and the nature of bacterial innovation," Nature, vol. 405, no. 6784, pp. 299-304, 2000.

[31] E. V. Sokurenko, V. Chesnokova, D. E. Dykhuizen et al., "Pathogenic adaptation of Escherichia coli by natural variation of the FimH adhesin," Proceedings of the National Academy of Sciences, vol. 95, no. 15, pp. 8922-8926, 1998.

[32] M. Sabaté, E. Moreno, T. Pérez, A. Andreu, and G. Prats, "Pathogenicity island markers in commensal and uropathogenic _Escherichia coli_isolates," Clinical Microbiology and Infection, vol. 12, no. 9, pp. 880-886, 2006.

[33] C. Carlos, M. M. Pires, N. C. Stoppe et al., "Escherichia coli phylogenetic group determination and its application in the identification of the major animal source of fecal contamination," BMC Microbiology, vol. 10, no. 1, pp. 1-10, 2010.

[34] H. Alizade, R. Ghanbarpour, and M. Aflatoonian, "Virulence Genotyping of Escherichia Coli Isolates from Diarrheic and Urinary Tract Infections in Relation to Phylogeny in Southeast of Iran," Trop Biomed, vol. 31, no. 1, pp. 174-182, 2014.

[35] N. Grude, N. Potaturkina-Nesterova, A. Jenkins et al., “A comparison of phylogenetic group, virulence factors and antibiotic resistance in Russian and Norwegian isolates of _Escherichia coli_from urinary tract infection," Clinical Microbiology and Infection, vol. 13, no. 2, pp. 208-211, 2007.

[36] E. Sáez-López, A. Cossa, R. Benmessaoud et al., "Characterization of vaginal Escherichia coli isolated from pregnant women in two different African sites," PLoS One, vol. 11, no. 7, article e0158695, 2016.

[37] A. Dadie, N. Kouassi, E. Dako, M. Dje, and M. Dosso, "Virulence, serotype and phylogenetic groups of diarrhoeagenic Escherichia coli isolated during digestive infections in Abidjan, Côte d'Ivoire," African Journal of Biotechnology, vol. 13, no. 9, 2014.
[38] A. Derakhshandeh, R. Firouzi, M. Moatamedifar, A. Motamedi, M. Bahadori, and Z. Naziri, "Phylogenetic analysis of Escherichia coli strains isolated from human samples," Molecular Biology Research Communications, vol. 2, no. 4, pp. 143-149, 2013.

[39] N. C. Stoppe, J. S. Silva, C. Carlos et al., "Worldwide phylogenetic group patterns of Escherichia coli from commensal human and wastewater treatment plant isolates," Frontiers in Microbiology, vol. 8, p. 2512, 2017.

[40] P. Escobar-Páramo, A. Le Menac’h, T. Le Gall et al., "Identification of forces shaping the commensal Escherichia coli genetic structure by comparing animal and human isolates," Environmental Microbiology, vol. 8, no. 11, pp. 1975-1984, 2006.

[41] E. Bok, J. Mazurek, A. Myc, M. Stosik, M. Wojciech, and K. Baldy-Chudzik, "Comparison of commensal escherichia coli isolates from adults and young children in Lubuskie province, Poland: Virulence potential, phylogeny and antimicrobial resistance," International journal of environmental research and public health, vol. 15, no. 4, p. 617, 2018.

[42] M. D. Blyton, S. J. Cornall, K. Kennedy, P. Colligon, and D. M. Gordon, "Sex-dependent competitive dominance of phylogenetic group B 2 E scherichia coli strains within human hosts," Environmental Microbiology Reports, vol. 6, no. 6, pp. 605610, 2014.

[43] B. Li, J. Y. Sun, L. Z. Han, X. H. Huang, Q. Fu, and Y. X. Ni, "Phylogenetic groups and pathogenicity island markers in fecalEscherichia coliisolates from asymptomatic humans in China," Applied and Environmental Microbiology, vol. 76, no. 19 , pp. 6698-6700, 2010. 